\title{
Assessment of Social Functioning among Adolescent School Children in Manipur: A Cross- sectional Study
}

\author{
Bishwalata Rajkumari', Konjengbam Erora 2 , Shyami Tarao ${ }^{3}$
}

${ }^{1}$ Associate Professor, ${ }^{2}$ Post-graduate Trainee, ${ }^{3}$ Assistant Professor, Department of Community Medicine, Jawaharlal Nehru Institute of Medical Sciences, Imphal, Manipur, India.

DOI: https://doi.org/10.24321/2349.2880.202106

I $\quad \begin{array}{llll}\mathbf{N} & \mathbf{F} & \mathbf{O}\end{array}$

\section{Corresponding Author:}

Konjengbam Erora, Department of Community Medicine, Jawaharlal Nehru Institute of Medical

Sciences, Imphal, Manipur, India.

E-mail Id:

konjengbamerora88@gmail.com

Orcid Id:

https://orcid.org/0000-0003-3620-5545

How to cite this article:

Rajkumari B, Erora K, Tarao S. Assessment of Social Functioning among Adolescent School Children in Manipur: A Cross-sectional Study. Ind J Youth Adol Health. 2021;8(2):1-7.

Date of Submission: 2021-04-24

Date of Acceptance: 2021-05-12
$\begin{array}{llllllll}\mathbf{A} & \mathbf{B} & \mathbf{S} & \mathbf{T} & \mathbf{R} & \mathbf{A} & \mathbf{C} & \mathbf{T}\end{array}$

Background: Globally $10-20 \%$ of adolescents experience mental health disorders. The greater part of disease being subclinical, identification has been a big challenge. Social functioning impairment is a sensitive indicator of underlying mental disorder. It forms a baseline for early identification of mental disorders.

Objectives: The study plans to assess the social functioning skill and its associated factors among adolescent school children.

Methods: The study was conducted among 3200 school-going adolescents studying in class 9th to 12th attending government and private schools located in Imphal-East and Bishnupur districts of Manipur recruited by stratified random sampling technique. The Child and Adolescent Social and Adaptive Functioning Scale (CASAFS), a validated tool consisting of 24 items designed to measure psychosocial functioning, was used. Descriptive and analytical statistics were generated taking $p<0.05$ as level of significance.

Results: A total of 25 schools were sampled with females constituting $52.3 \%$. Overall $21.8 \%$ had good social adaptive functioning skills whereas $29.6 \%$ showed poor skills. Around $36.3 \%$ showed poor performance in 'peer relationship domain' and $27.1 \%$ showed poor performance in 'self-care/ home domain'. Socio-demographic variables such as age, gender, number of siblings, and education of parents were found to be significantly associated with having 'good social adaptive functioning $\operatorname{skill}^{\prime}(p<0.05)$.

Conclusion: A significant proportion of adolescents face psychosocial issues in their day to day life. Improving social skills will be an effective intervention to reduce mental disorders.

Keywords: CASAF Scale, Social Functioning, Adolescent Mental Health 


\section{Introduction}

World Health Organization (WHO) defines 'adolescents' as individuals in 10 to 19 years age group, a developmental stage that signifies an individual's transition from childhood into adulthood. During this crucial phase, they are exposed to dramatic physical, psychological, emotional, and social changes, requiring them to observe, understand, and develop coping, problem solving, and interpersonal skills. It is a period when they are more likely to engage in risky and thrill-seeking behaviour posing a significant risk for injury, physical, and mental health issues. ${ }^{1}$

Around 1.2 billion people, or 1 in 6 of the world's population, are adolescents. With a population of 253 million, India is home to $21 \%$ of the world's adolescents. ${ }^{2}$ Mental health disorders are experienced by approximately $10-20 \%$ of adolescents globally, and most of them are unable to receive proper diagnosis as well as treatment. ${ }^{3}$

'Adolescent mental health' has become a prime public health concern as it strongly impacts their physical, social, and psychosocial aspects. Mental disorders when kept improperly managed, extend into their adulthood and significantly compromise their potential to live a productive life. ${ }^{4}$ Identification and quantification of mental disorders have remained a big challenge. A diagnosis of mental disorder requires not only the presence of specific symptoms of psychopathology but also impairment in social functioning. Social functioning is a sensitive indicator of underlying mental disorders even before the presence of clinical signs and symptoms. ${ }^{5}$

Formulating an effective public health intervention for these adolescents requires data on disease burden and its interaction with various factors. Despite the vulnerability to various factors, adolescence-phase appears particularly receptive to the positive influences of youth development strategies, socio-emotional learning, and behavioural modelling. Thus, it presents a critical period for remedial intervention to achieve maximum effectiveness. ${ }^{6}$ Early identification and effective management of adolescents with poor psychosocial skills and undiagnosed mental disorders can prevent many psychiatric disorders at their nascent stage. ${ }^{5}$

In the absence of studies addressing these issues, there exists a lacuna in knowledge regarding the burden of mental health disorders among adolescents in the north-eastern part of India. Thus, this study was conducted to assess the level of social functioning skills and its associated factors among school-going adolescents in a state of North East India.

\section{Materials and Methods}

This cross-sectional study was conducted among adolescents studying in classes 9 to 12 in schools located in Imphal-East and Bishnupur districts of Manipur from November 2018 to March 2020. The adolescents who refused to participate and those who were absent on the day of data collection were excluded from the study.

Sample Size and Sampling: Based on the prevalence of mental health morbidity of $22.7 \%^{7}$ with an absolute allowable error of 1.5 and at $95 \%$ confidence level with an estimated non-response rate of $10 \%$ using the formula for single proportion, the calculated sample was found to be 3119 rounded off to 3200 . A stratified random sampling technique was used. Schools were stratified by type i.e. government schools and private schools for each district. Equal numbers of students were selected from each district i.e. 1600 . From the list of government high schools and higher secondary schools of the particular district, the schools were selected using lottery method. Similarly from the listed private schools in the district, schools were selected by lottery method. All eligible adolescents from selected schools were recruited. Sampling of schools continued till the required sample size was reached for each category of schools for each district, that is, 800 each from government and private schools in the two districts. Since the school enrollment is very poor in government schools, if the required sample size was not met after sampling all eligible government schools in the district, the remaining was taken up from private schools.

Study Tool and Technique: A predesigned self-administered questionnaire containing two parts, was used. The 1st part consisted of the socio-demographic profile of respondents and the 2nd part consisted of the Child and Adolescent Social and Adaptive Functioning (CASAF) Scale, a validated tool consisting of 24 items designed to measure psychosocial functioning. CASAF scale consists of four subscales examining functioning in key social role areas relevant to children and adolescents, namely (a) School performance, (b) Peer relationships, (c) Family relationships, and (d) Home duties/ self-care. ${ }^{5} \mathrm{~A}$ Likert scale scoring was done for each question ranging from $1=$ never, 2 = sometimes, $3=$ often, and $4=$ always. With the total scores ranging from 24-96, the scores were summated across for each student.

Operational Definition: The respondents scoring below the 25th percentile of the total score were classified as having "low social adaptive functioning skill", between 25th to 75 th percentile as "average social adaptive functioning skill", and above 75th percentile as having "good social adaptive functioning skill".

Statistical Analysis: The collected data were analysed using SPSS Version 20. Socio-demographic attributes were presented using descriptive statistics like mean, standard deviation, and proportions. Analytical statistics, like chisquare test, was used. A p-value of $<0.05$ was taken as the level of significance. 
Ethical Issues: Ethical approval for the study was obtained from the Institutional Ethics Committee for Protocol No. 117(10)PGT 2018 version 02, submitted on 19/09/2018. Written permission was obtained from all participating school authorities and parents. Verbal assent was obtained from all the participants.

\section{Results}

A total of 25 schools ( 15 government and 10 private) were sampled for the study. The age of students ranged from 14 to 19 years with a mean (SD) age of 16.1 (1.2) years and females constituting 52.3\%. Majority of the students were in 11 th standard (29\%), Meitei by religion (47\%), and had 4 or more siblings (37.8\%). Most of the respondents (30\%) had their parents educated up to primary or high school level.

Table 1 shows the responses to the items in different domains by the students. Social functioning was found highest for 'school performance domain' with $>80 \%$ of respondents scoring average or good. 'Peer relationship domain' has more than $1 / 3$ rd (36.3\%) of the students showing low social adaptive functioning skill. Overall, $21.8 \%$ had good social adaptive functioning skill whereas $29.6 \%$ showed low social adaptive functioning skill (Table 2).

Females were found to have significantly better social adaptive functioning skills as compared to males ( $p=$ 0.038 ). Those belonging to the age group of $14-15$ years have significantly higher good social functioning skills as compared to other age groups $(p=0.026)$. Higher number of siblings $(p=0.04)$ and higher parental education were significantly associated with good social functioning. Social functioning skills were poorer among respondents studying in government schools as compared to those in private schools ( $p=0.027$ ) (Table 3$)$.

Table I.Assessment of the Respondents by Different Domains

\begin{tabular}{|c|c|c|c|c|c|}
\hline Domains & $\begin{array}{l}\text { Never } \\
\mathbf{N}(\%)\end{array}$ & $\begin{array}{l}\text { Sometimes } \\
\mathbf{N}(\%)\end{array}$ & $\begin{array}{l}\text { Often } \\
\mathrm{N}(\%)\end{array}$ & $\begin{array}{l}\text { Always } \\
\text { N (\%) }\end{array}$ & $\begin{array}{c}\text { Does Not } \\
\text { Apply to } \\
\text { Me }\end{array}$ \\
\hline \multicolumn{6}{|l|}{ School performance domain } \\
\hline I get good marks in maths & $327(10.2)$ & $2039(63.7)$ & $541(16.9)$ & $293(9.2)$ & - \\
\hline I get good marks in science & $300(9.4)$ & $1863(58.2)$ & $673(21)$ & $364(11.4)$ & - \\
\hline I get good marks in social science & $184(5.8)$ & $1640(51.3)$ & $890(27.8)$ & $486(15.2)$ & - \\
\hline I get good marks in English & $165(5.2)$ & $1238(38.7)$ & $1082(33.8)$ & $715(22.3)$ & - \\
\hline I have trouble with my school work & $525(16.4)$ & $1883(58.8)$ & $368(11.5)$ & $424(13.3)$ & - \\
\hline I am successful with my school work & $185(5.8)$ & $1003(31.3)$ & 1007 (31.5) & $1005(3.4)$ & - \\
\hline \multicolumn{6}{|l|}{ Peer relationship domain } \\
\hline I go out to places with my friends & $225(7)$ & $2033(63.5)$ & $596(18.6)$ & $348(10.8)$ & - \\
\hline I have friends of opposite sex & $179(5.6)$ & $1192(37.3)$ & $785(24.5)$ & 1049 (32.6) & - \\
\hline I go to parties or school dances & $364(11.4)$ & $1862(58.2)$ & $434(13.6)$ & $540(16.9)$ & - \\
\hline $\begin{array}{l}\text { I have at least one or two special } \\
\text { friends }\end{array}$ & $183(5.7)$ & $675(21.1)$ & $832(26.4)$ & $1510(47.2)$ & - \\
\hline I spend most of my spare time alone & $547(17.1)$ & $1571(49.1)$ & $600(18.8)$ & $482(15.1)$ & - \\
\hline I have difficulty making friends & $1102(34.4)$ & $1253(39.2)$ & $424(13.3)$ & $421(13.2)$ & - \\
\hline \multicolumn{6}{|l|}{ Family relationship domain } \\
\hline I have good relation with my mother & $95(3)$ & $448(14)$ & $613(19.2)$ & $2021(63.2)$ & $23(0.7)$ \\
\hline I have good relation with my father & $240(7.5)$ & $616(19.3)$ & $648(20.3)$ & $1680(52.5)$ & $16(5)$ \\
\hline I get on well with my siblings & $88(2.8)$ & $511(16)$ & $464(14.5)$ & $2137(66.8)$ & - \\
\hline I get on well with my relatives & $233(7.3)$ & $612(19.1)$ & $773(24.2)$ & $1582(49.4)$ & - \\
\hline I have fight with my parents & $446(13.9)$ & $273(8.5)$ & $1348(42.1)$ & $1133(35.4)$ & - \\
\hline $\begin{array}{l}\text { I have an adult who I can talk to if I } \\
\text { have a problem }\end{array}$ & 606 (18.9) & $860(26.9)$ & $570(17.8)$ & $1164(36.4)$ & - \\
\hline \multicolumn{6}{|l|}{ Home duties/ Self-care domain } \\
\hline I help around the house & $92(2.9)$ & $940(29.3)$ & $95(28.6)$ & $1253(39.2)$ & - \\
\hline
\end{tabular}




\begin{tabular}{|c|c|c|c|c|c|}
\hline I keep my rooms and belonging tidy & $132(4.1)$ & $683(21.3)$ & $761(23.8)$ & $1624(50.8)$ & - \\
\hline I keep my clothes clean and tidy & $66(2.1)$ & $607(19)$ & $637(19.9)$ & $1890(59.1)$ & - \\
\hline I shower and keep myself clean & $206(6.4)$ & $563(17.6)$ & $673(21)$ & $1758(54.9)$ & - \\
\hline I help with cooking at home & $302(9.6)$ & $1175(36.7)$ & $767(24)$ & $951(29.7)$ & - \\
\hline I help up in cleaningup after meals & $280(8.8)$ & $998(31.2)$ & $626(19.6)$ & $1296(90.5)$ & - \\
\hline
\end{tabular}

Table 2.Distribution of Performance by Domains of CASAF Scale

\begin{tabular}{|c|c|c|c|}
\hline \multirow{2}{*}{ Domains } & \multicolumn{3}{|c|}{ Social Adaptive Functioning Skill } \\
\cline { 2 - 4 } & Poor & Average & Good \\
\hline School performance & $636(19.9)$ & $1926(60.2)$ & $636(19.9)$ \\
\hline Family relationship domain & $946(29.7)$ & $1584(49.5)$ & $667(20.8)$ \\
\hline Peer relationship domain & $1161(36.3)$ & $1447(45.2)$ & $592(18.5)$ \\
\hline Self-care/ home domain & $870(27.1)$ & $1610(50.3)$ & $720(22.5)$ \\
\hline Total score & $946(29.6)$ & $1557(48.7)$ & $692(21.8)$ \\
\hline
\end{tabular}

Table 3.Associationbetween Social Adaptive Functioning Skills of the Respondents with Socio-demographic Factors

$N=3200$

\begin{tabular}{|c|c|c|c|c|c|}
\hline \multirow{2}{*}{\multicolumn{2}{|c|}{ Variable }} & \multicolumn{3}{|c|}{ Social Adaptive Functioning Skill } & \multirow{4}{*}{$\begin{array}{r}\text { p-value } \\
0.038\end{array}$} \\
\hline & & \multirow{2}{*}{$\begin{array}{c}\text { Poor } \\
\text { N (\%) } \\
417(24.9) \\
\end{array}$} & \multirow{2}{*}{$\begin{array}{c}\begin{array}{c}\text { Average } \\
\text { N (\%) }\end{array} \\
764(45.6) \\
\end{array}$} & \multirow{2}{*}{$\begin{array}{c}\begin{array}{c}\text { Good } \\
\text { N (\%) }\end{array} \\
495(29.5)\end{array}$} & \\
\hline Gender & Female & & & & \\
\hline gerraer & Male & $529(34.7)$ & $793(52)$ & $202(13.3)$ & \\
\hline \multirow{4}{*}{ Class } & 9th & $172(20.7)$ & $399(48)$ & $260(31.3)$ & \multirow{4}{*}{0.016} \\
\hline & 10th & $243(31.8)$ & $400(52.4)$ & $121(15.8)$ & \\
\hline & 11th & $283(32.3)$ & $422(48.1)$ & $172(19.6)$ & \\
\hline & 12th & $248(34.1)$ & $336(46.2)$ & $144(19.8)$ & \\
\hline \multirow{3}{*}{ Age (years) } & $14-15$ & 255 (25.9) & $452(45.9)$ & $278(28.2)$ & \multirow{3}{*}{0.026} \\
\hline & $16-17$ & $473(31.4)$ & $765(50.8)$ & $268(17.8)$ & \\
\hline & $18-19$ & $218(30.7)$ & $340(48)$ & $151(21.3)$ & \\
\hline \multirow{5}{*}{ Religion } & Hindu & $130(23)$ & $261(46.2)$ & $174(30.8)$ & \multirow{5}{*}{0.002} \\
\hline & Muslim & $52(17.5)$ & $180(60.6)$ & $65(21.9)$ & \\
\hline & Christian & $395(47.2)$ & $373(44.6)$ & $68(8.1)$ & \\
\hline & Meitei & $369(24.6)$ & $743(49.3)$ & $390(26.0)$ & \\
\hline & Others & $\mathrm{Nil}$ & $\mathrm{Nil}$ & Nil & \\
\hline \multirow{5}{*}{ Number of siblings } & None & $21(2.2)$ & $39(2.5)$ & $15(2.2)$ & \multirow{5}{*}{0.04} \\
\hline & One & $126(13.3)$ & 181 (11.6) & $93(13.3)$ & \\
\hline & Two & $228(24.1)$ & 385 (24.7) & $179(25.7)$ & \\
\hline & Three & $152(16.1)$ & 367 (23.6) & $203(29.1)$ & \\
\hline & Four and above & $419(44.3)$ & $585(37.6)$ & $207(29.7)$ & \\
\hline \multirow{2}{*}{ Type of school } & Government & $358(32.5)$ & $536(48.7)$ & $206(18.7)$ & \multirow{2}{*}{0.027} \\
\hline & Private & $588(28.0)$ & $1021(48.6)$ & $491(23.4)$ & \\
\hline
\end{tabular}




\begin{tabular}{|c|c|c|c|c|c|}
\hline \multirow{5}{*}{$\begin{array}{l}\text { Mother's } \\
\text { educational } \\
\text { status }\end{array}$} & Illiterate & $309(31.8)$ & $454(46.8)$ & $208(21.4)$ & \multirow{5}{*}{0.001} \\
\hline & Primary and middle & $304(30)$ & $501(49.4)$ & $210(20.7)$ & \\
\hline & 10th passed & $180(28.2)$ & $318(49.8)$ & $141(22.1)$ & \\
\hline & 12th passed & $114(32.4)$ & $176(50)$ & $62(17.6)$ & \\
\hline & Graduate and above & $39(17.5)$ & $108(48.4)$ & $76(34.1)$ & \\
\hline \multirow{5}{*}{$\begin{array}{c}\text { Father's } \\
\text { educational } \\
\text { status }\end{array}$} & Illiterate & $126(23.0)$ & $332(60.6)$ & $90(16.4)$ & \multirow{5}{*}{0.001} \\
\hline & Primary and middle & $353(36.5)$ & $432(44.6)$ & $183(18.9)$ & \\
\hline & 10th passed & $262(33.0)$ & $348(43.8)$ & $185(23.3)$ & \\
\hline & 12th passed & $109(24.2)$ & $236(52.4)$ & $105(23.3)$ & \\
\hline & Graduate and above & $96(21.9)$ & 209 (47.6) & $134(30.5)$ & \\
\hline
\end{tabular}

\section{Discussion}

This study conducted among the adolescents in two districts of Manipur is one of the few studies undertaken to determine the social functioning of adolescent students in the state. In this study, majority of the respondents were 15 years old (30.6\%) with an almost equal proportion of adolescents in each of the classes from 9th to 12th standard which is similar to a previous study. ${ }^{8}$ Most of the respondents' mothers were educated up to primary and middle school (31.7\%) and $30.3 \%$ were illiterate; similar findings were reported in other studies. ${ }^{9-11}$ Majority of the adolescents had 4 and more siblings (37.8\%). This may be due to the fact that in our study, a large proportion of the respondents was from rural areas and had a lower parental literacy, which may have influenced their adoption of family planning.

In the school performance domain, the proportion of respondents reporting as 'always successful in school work' was $3.4 \%$ which was much lower than the proportion of $15.3 \%$ as reported in an earlier study. ${ }^{8}$ The difference may be due to the fact that this study includes a large proportion of government school adolescents as compared to the other study where more private schools were included. About $15.1 \%$ of the adolescents 'always spent their spare time by themselves' and $13.2 \%$ 'always found it difficult to make friends' in the present study. Kandel D et al. stated that lack of satisfaction with academic performance emerged as the most important predictor of depression. In general, adolescents with elevated depressive symptoms display lower levels of social functioning, including isolation from peers. ${ }^{12,13}$ About $63.2 \%$ of the respondents had a good relationship with their mothers whereas only $52.5 \%$ had a good relationship with their fathers which is similar to another study conducted by Deb S et al. ${ }^{14}$ The adolescent's attempts toward individualisation and developing a concept of self may affect the parent-child relationship and imbalance the family environment causing conflicts leading to stress and anxiety. ${ }^{15,16}$ Wel $\mathrm{F}$ et al. stated that parental bonds have a lasting significant influence on the well-being of adolescents. ${ }^{17}$ In this study, only half of the respondents (50.8\%) reported that they 'always keep their rooms and belongings tidy'. Adolescents with mental disorders often fail in daily self-care routines and in many instances, cannot maintain steady friendships, relationships, or employment. ${ }^{15,18,19}$ In this study, the 'good' performance score in the four domains i.e. school performance (19.9\%), peer relationship (18.5\%), family relationships (20.8\%), and home/ self-care $(22.5 \%)$ were lower than that reported by other authors. ${ }^{15,20}$ This study showed females (30\%) as having a higher level of good social functioning as compared to males (13.3\%). Few surveys in literature have already reported gender differences in social functioning skills with females engaging in more social acts as compared to males. ${ }^{9,14,15,21}$ This study found adolescent students in 12th standard as having the poorest social functioning skills (34.1\%), similar to findings reported by previous studies. ${ }^{9,16-18,22-24}$ A possible explanation for worse social functioning among the 12th standard students may be the presence of a higher academic pressure due to ensuing board exams. The study reveals that adolescents with more siblings had better social functioning skill which contradicts a study done by Fatiregun et al. ${ }^{25}$ The reason may be that adolescents with a higher number of siblings may be able to share their emotions and feelings which may help them in coping in times of stress and crisis. ${ }^{26}$

The strength of our study is that it was done in a large sample population of 3200 using a validated tool covering both government and private schools. The study covered Bishnupur District where majority of the people belong to rural areas and Imphal-east most of the population is urban. The study's limitations are that adolescents studying in lower classes could not be included. Moreover, absentees on the day of visit and school dropouts were not included which may be an underestimation of the disease burden as they are more likely to have mental disorders; hence, findings of the present study cannot be generalised.

\section{Conclusion}

The study highlighted that a significant proportion of 
school-going adolescents face psychosocial issues in their day to day life. Improving social skills will be an effective intervention to reduce mental disorders. There is a need for a strong multi-sectoral response to this common but ignored important public health problem.

\section{Sources of Funding: None \\ Conflict of Interest: None}

\section{References}

1. World Health Organization [Internet]. Adolescent mental health: time for action. Geneva; 2019 [cited 2019 Aug 9]. Available from: https://www.who.int/ pmnch/knowledge/publications/AMH.pdf

2. World Health Organization [Internet]. Adolescent health. The missing population in universal health coverage. Geneva; 2019 [cited 2019 Aug 10]. Available from: https://www.who.int/pmnch/media/events/ Adolescent-Health-Missing-Population-in-UHC. pdf?ua $=1$

3. World Health Organization [Internet]. Global Health Estimates; 2019 [cited 2019 Aug 20]. Available from: https://www.who.int/healthinfo/global_burden_ disease/en/

4. World Health Organisation [Internet]. Adolescents and young adult health. Geneva; 2019 [cited 2019 Sep 9]. Available from: https://www.who.int/news-room/factsheets/detail/adolescents-health-risks-and-solutions

5. Price CS, Spence SH, Sheffield J, Donovan C. The development and psychometric properties of a measure of social and adaptive functioning for children and adolescents. J Clin Child Adolesc Psychol. 2002;31:11122. [PubMed] [Google Scholar]

6. Ministry of Health \& Family Welfare, Government of India [Internet]. New Pathways, New Hope: National Mental Health Policy of India. 2014; [cited 2018 Oct]. Available from: https://nhm.gov.in/images/pdf/ National_Health_Mental_Policy.pdf

7. Gupta AK, Mongia M, Garg AK. A descriptive study of behavioral problems in schoolgoing children. Ind Psychiatry J. 2017;26:91-4. [PubMed] [Google Scholar]

8. Rajkumari B, Rajkumar BS, Nula P. Assessment of social and functional skills and its correlates among adolescents-across-sectional study. Ann Int Med Den Res. 2017;3(4):CM05-9. [Google Scholar]

9. Singh K, Junnarkar M, Sharma S. Anxiety, stress, depression, and psychosocial functioning of Indian adolescents. Ind J Psychiatry. 2015;57(4):367-74. [PubMed] [Google Scholar]

10. Timalsina M, Kafle M, Timalsina R. Psychosocial problems among school going adolescents in Nepal. Psychiatry J. 2018;1:1-6. [PubMed] [Google Scholar]

11. Bhosale S, Singru SA, Khismatrao D. Study of psychosocial problems among adolescent students in Pune, India. Al Ameen J Med Sci. 2015;8(2):150-5. [Google Scholar]

12. Kandel D, Davies M. Epidemiology of depressive mood in adolescents: an empirical study. Arch Gen Psychiatry. 1982;39:1205-12. [PubMed] [Google Scholar]

13. Pathak R, Sharma RC, Parvan UC, Gupta BP, Ojha RK, Goel NK. Behavioural and emotional problems in school going adolescents. Australas Med J. 2011;4(1):1521. [PubMed] [Google Scholar]

14. Deb S, Chatterjee P, Walsh K. Anxiety among high school students in India: comparisons across gender, school type, social strata, and perceptions of quality time with parents. AJEDP. 2010;109(1):18-31. [Google Scholar]

15. Sanmartín R, Inglés CJ, Vicent M, Gonzálvez C, DíazHerrero Á, García-Fernández JM. Positive and negative affect as predictors of social functioning in Spanish children. PLoS One. 2018;13(8):1-25. [PubMed] [Google Scholar]

16. Muzammil K, Kishore S, Semwal J. Prevalence of psychosocial problems among adolescents in district Dehradun, Uttarakhand. Ind J Public Health. 2009;53:1821. [PubMed] [Google Scholar]

17. Van Wel F, Ter Bogt T, Raaijmakers Q. Changes in the parental bond and the well-being of adolescents and young adults. Adolescence. 2002;37(146):317-33. [PubMed] [Google Scholar]

18. Vashisht A, Gadi NA, Singh J, Mukherji MP, Pathak R, Mishra P. Prevalence of depression and assessment of risk factors among school going adolescents. Ind J Comm Health. 2014;26(2):196-9. [Google Scholar]

19. Aziz S, Tariq N. Depression, anxiety, and stress in relation to life satisfaction and academic performance of adolescents. Pak J Physiol. 2019;15(1):52-5. [Google Scholar]

20. da Silva RA, Horta BL, Pontes LM, Faria AD, Souza LD, Cruzeiro AL, Pinheiro RT. Psychological well-being and adolescence: associated factors. Cad Saude Publica. 2007;23(5):1113-8. [PubMed]

21. Dietz T, Kalof L, Stern PC. Gender, values, and environmentalism. Soc Sci Q. 2002;83:353-64. [Google Scholar]

22. Jayanthi P, Thirunavukarasu M, Rajkumar R. Academic stress and depression among adolescents: a crosssectional study. Indian Pediatr. 2015;52:217-9. [PubMed] [Google Scholar]

23. Bista B, Thapa P, Sapkota D, Singh BS, Pokharel PK. Psychosocial problems among adolescent students: an exploratory study in the central region of Nepal. Front Public Health.2016:4:158-62. [PubMed] [Google Scholar]

24. Puig-Antich J, Kaufman J, Ryan ND, Williamson DE, Dahl RE, Lukens E, Todak G, Ambrosini P, Rabinovich $\mathrm{H}$, Nelson $\mathrm{B}$. The psychosocial functioning and family 
environment of depressed adolescents. J Am Acad Child Adolesc Psychiatry. 1993;32:245-53. [PubMed] [Google Scholar]

25. Fatiregun AA, Kumapayi TE. Prevalence and correlates of depressive symptoms among in-school adolescents in a rural district in southwest Nigeria. J Adolesc. 2014 Feb;37(2):197-203. [PubMed] [Google Scholar]

26. Slotkin J, Forehand R, Fauber R, McCombs A, Long $\mathrm{N}$. Parent-completed and adolescent-completed CDIs: relationship to adolescent social and cognitive functioning. J Abnormal Child Psychol. 1988;16:207-17. [PubMed] [Google Scholar] 